\title{
Presuppositions as Cancellable Inferences
}

\author{
Fabrizio Macagno and Alessandro Capone
}

\begin{abstract}
The phenomenon of presupposition suspension can be analyzed in terms of explicatures and the corresponding non-presumptive interpretative reasoning underlying it. On the view presented in this paper, the polyphonic articulation of an utterance at different levels can be used to explain cases in which presuppositions are suspended. Presuppositional suspensions indicate that the presumptive reading does not hold and a different interpretation is needed. Utterances can display various types of polyphonic structures, accounting for the speaker's and the hearer's commitments. A speaker can be held directly responsible for what he says, but he is committed only indirectly to what he presupposes, i.e. what is uttered by a second voice (the second utterer or enunciator) representing what the common opinion accepts to be true. The reconstruction of the pragmatic structure of an utterance is guided by a complex type of reasoning, which can be represented as an argumentative abductive pattern, grounded on hierarchies of presumptions. By comparing the possible presumptions associated with the explicit meaning and the contextual information, the hearer can find a best possible explanation of the intended effect of the utterance.
\end{abstract}

Keywords Presupposition - Explicatures - Conversational implicatures - Cancellability • Indirect reports • Polyphony

Fabrizio Macagno would like to thank the Fundação para a Ciências e a Tecnologia for the research grants no. IF/00945/2013, PTDC/IVC-HFC/1817/2014, and PTDC/MHC-FIL/0521/2014.

F. Macagno

ArgLab, IFL, Faculdade de Ciências Sociais e Humanas, Universidade Nova de Lisboa, Av. de Berna 26C1069-061 Lisboa, Portugal

e-mail: fabrizio.macagno@fcsh.unl.pt

\author{
A. Capone $(\bowtie)$ \\ Department of Cognitive Science, University of Messina, Messina, Italy \\ e-mail: alessandro.caponis@gmail.com
}




\section{Introduction}

Because "utterance" is hard to define, and its meaning is both in the building elements of an utterance (lexical units) and in the subsequent utterances produced in response, pragmatics, which is also defined as a theory of meaning in context, has been looking for meaning ingredients both inside and outside the utterance. (Kecskes 2013: 8)

The projection and suspension of presuppositions is a problem in which the interplay between semantics and pragmatics emerges, and can be addressed starting from Jaszczolt's (2005) important notion of merger representations, loci where semantic and pragmatic information is merged through a suitable algorithm. Pragmatic presuppositions can be regarded as background beliefs, proposition whose truth the speaker takes for granted (or seems to take for granted) in making his statement (Stalnaker 1974: 472). In this sense, the use of a sentence can be inappropriate unless the speaker presupposed a specific proposition (Stalnaker 1973: 451). This distinction between the grammatical (sentential) level and the pragmatic one leads to the problem of presupposition triggers, or rather the problem of analyzing how the pragmatic presuppositions are triggered, or how the semantic presuppositions are projected or suspended (Heim 1992), such as in case of negation, embedding, or other syntactic or pragmatic phenomena.

The goal of this paper is to try to explain some cases of presupposition suspension as phenomena of non-presumptive or non-prototypical interpretation of an utterance (Simons 2013: 339). On this view, an utterance is analyzed as the subject matter of a process of interpretation, in which the hearer relies on presumptive reasoning to reconstruct the speaker's communicative intention (Levinson 2000; Jaszczolt 2005, 2010; Huang 2007; Mey 2001). Presumptive interpretations may fail in different respects and under various circumstances. In this paper we will focus on a specific dimension of presumptive and non-presumptive interpretation, namely the distinction between the various types of polyphonic structures. If we consider the relationship between a speaker and his utterances, the latter can be regarded in terms of commitments. The voice that is responsible for an utterance is also responsible for what is meant. However, utterances may deploy a variety of voices (a polyphony, building on the idea of Bakhtin 1981, 1986) or rather a complex structure of indirect reports, in which different utterers (or enunciators) can be distinguished and held responsible for different implicit speech acts (see Capone 2010a, b).

The phenomena of presupposition suspension can be regarded as arising from the discrepancy between the presumptive reading of an utterance and its nonprototypical meaning. Some utterances can be used to express a communicative intention that would not result from the default meaning attributed to it. Some utterances, considering the co-text, the context, and the background assumptions shared by the interlocutors, appear to be inconsistent or even self-contradictory. Such an apparent failure or problem to express the speaker's communicative intention can be the trigger of a non-defaultive reading of the utterance. Sometimes the defaultive meaning of a predicate can be subject to default, and another meaning is retrieved. The prototypical polyphony of an utterance can be modified, and the 
speaker can refuse meta-linguistically (also through a meta-linguistic negation) the commitments resulting from another's voice. In this sense, an internal dialogue arises, in which the presuppositions triggered by another utterer's utterance are commented on or refused. The presumptive interpretation of an utterance as a specific speech act (namely as having a specific illocutionary or perlocutionary force, see Kissine 2012) can be also subject to default involving a suspension of the presumptive presuppositions. When this prototypical interpretation fails, a complex mechanism of reconstruction of the speaker's intention is triggered, aimed at bringing to light the communicative intention.

We will show how presupposition suspension can be thought of as the trigger of a more complex process of meaning explanation at different levels. In particular, the reconstruction of the illocutionary force of an utterance and the retrieval of the logical form of the proposition expressed by it enriched with pragmatic and contextual information (explicatures) can show how presupposition suspensions can be rather thought of cases of non-defaultive interpretations.

\section{Presumptions, Meaning, and Explicatures}

In pragmatics, the reconstruction of the communicative "meaning" of a speech act can be considered as the result of a process of reasoning, aimed at abducing an intention, i.e. the speaker's communicative intention, from an utterance. As Mey (2001: 93-94) puts it:

[...] speech acts are produced not in the solitary philosopher's think-tank, but in actual situations of use, by people having something 'in mind'. Such a production naturally presupposes a 'producer' and a 'consumer', human agents, whose intentions are relevant and indispensable to the correct understanding and description of their utterances, quite contrary to the constructed, non-use-oriented examples of most grammarians and philosophers.

A speaker can convey his message relying on the hearer's sharing the same knowledge of the language and pragmatic principles, through which he can make his communicative intention explicit (Capone 2013b: 134). However, the transition from the linguistic content to the communicative intention is not straightforward. Linguistic elements can be used with a meaning different from the widely known pattern of its use (Mel'cuk 1997; Hamblin 1970: 295). ${ }^{1}$ Sentence types (such as declarative, interrogative, expressive, etc.) can be used to perform speech acts different from the ones prototypically associated with them (Capone 2010a; Kecskes and Zhang 2009; Kecskes 2008: 389). In this sense, the reconstruction of meaning can be regarded as facilitated and guided by presumptions, i.e. preferential and

\footnotetext{
${ }^{1}$ As Jaszczolt (2010) claims, "Since the rise of radical pragmatics in the late 1970s, semantics has begun to grow to include not only the study of the meaning of the sentence, but also those aspects of meaning intended by the author (speaker, writer) of this sentence which transform sentence meaning into the speaker's intended, explicit meaning or what is said."
} 
defaultive uses of linguistic elements or syntactic constructions (for a contextual development of the idea of presumptive interpretation, see Kecskes and Zhang 2009: 337).

The distinction between prototypical (defaultive) and non-prototypical meaning is clearly underscored by Jaszczolt's (2005) work on default semantics and on merger representations. Default semantics provides a model of discourse interpretation which is neo-Gricean and (fundamentally) contextualist. Such a model is founded on the Model Speaker's intention by the Model Addressee and utilizes the tools of truth-conditions to the representation of utterances. Merger Representations, in Jaszczolt's model, are representations in which semantic and pragmatic interpretations are integrated following a suitable algorithm, which can captured by the following (see Jaszczolt 2010):

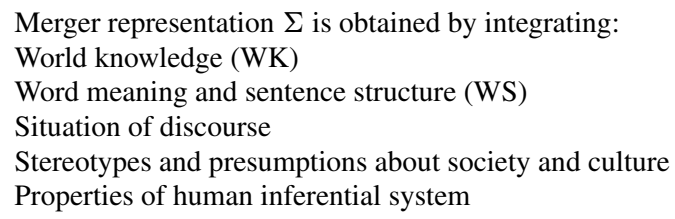

As Jaszczolt (2010) claims, the idea that syntactic and semantic information have a privileged status and are essentially the point of departure for pragmatic processing needs to be discarded. Such a view would amount to accepting that pragmatic processing provides only pragmatic additions and embellishments of logical forms. A more holistic approach regards semantic and pragmatic information as interacting on a par within the Merger Representation. Sometimes the result of pragmatic processing amounts to meaning subtraction (rather than to additions). Jaszczolt (2010) provides a more refined view of merger representations intended as pragmatic composition. A merger representation $\Sigma$ is obtained by integrating the following components: (a) a combination of word meaning and sentence structure (WS); (b) sociocultural and world-knowledge defaults; (c) cognitive defaults; and (d) conscious pragmatic inference (from situation of discourse, social and cultural assumptions, and world knowledge). The picture that emerges provides for a distinction between default meanings on the one hand, and on the other hand human reasoning used to calculate pragmatic inference, sometimes leading to the integration (or the abortion) of default meanings.

The aforementioned account provides a clear outline of the concept of default reconstruction of an utterance. Default interpretation can be thought of as the presumptive association between an utterance and its communicative effects, namely the pragmatic inferences it triggers and its effects on the communicative setting (Grice 1975, 1989: 220; Levinson 1983: 97). Such effects are the result of the propositional meaning, the possible inferences, the presuppositions, and the context and co-text of the utterance. The automatic, defaultive interpretation that usually characterizes communication can be described as based on a process of presumptive, i.e. defaultive and provisional, reasoning (Levinson 2000: 238; Atlas and Levinson 
1981; Walton 1996; Macagno and Walton 2014: 180-182) having the following structure (Rescher 2006: 33):

Premise 1: $P$ (the proposition representing the presumption) obtains whenever the condition $C$ obtains unless and until the standard default proviso $D$ (to the effect that countervailing evidence is at hand) obtains (Rule).

Premise 2: Condition $C$ obtains (Fact).

Premise 3: Proviso $D$ does not obtain (Exception).

Conclusion: $P$ obtains.

Presumptive reasoning is the process frequently underlying the mechanism of reconstruction of explicit meaning called explicature. Explicatures are normally developments of logical form (in the sense of Carston (2002)), although we grant that it is not always the case that the relationship between the explicature and the logical form is one of entailment. Sometimes the development of the logical form involves subtractions of meaning, as happens in ironic or metaphorical interpretations. An explicature is certainly a richer proposition than the minimal proposition expressed by the logical form. ${ }^{2}$ The development of the explicature involves (a) saturation of variables; (b) ambiguity resolution; (c) the attribution of reference to certain unarticulated constituents (e.g. implicit argument studied by Roeper as in [The ship was sunk _ to PRO collect the insurance]); (d) free enrichment à la Carston. In this sense, explicatures are cases in which implicated meaning intrudes into propositional meaning. A truth-evaluable proposition results from combining the linguistic materials of a sentence with the pragmatic elements of the corresponding explicature.

This type of reconstructions, aimed at expressing what a statement means by taking into account the context in which it has been uttered and other pragmatic factors, have been usually considered by both neo-Griceans and Relevance theorists as automatic and non-reflective inferences (Capone 2006; Macagno and Walton 2013). However, when the presumptions on which the habitual interpretation of an utterance is based fail, the process of reconstruction becomes more complex, based on different types of reasoning.

Explicatures, and consequently the reconstruction of meaning, are regarded as uncancellable, as they are essentially related with the felicity of the speech act expressed by the utterance. In other words, the hearer's reply presupposes the understanding of the speaker's move, i.e. the interpretation of an ambiguous lexical expression and the explicature that disambiguates the expression. When such an explicature is not challenged, it becomes part of the presuppositions on which the discourse is based (Stalnaker 2002; Allan 2013). In this sense, explicatures cannot be cancelled, as this would amount to a cancellation of a fundamental pragmatic presupposition (Capone 2006, 2009).

The problem of presupposition and presupposition suspension can be addressed considering such suspensions as indicators of a renegotiation of the preferential

\footnotetext{
${ }^{2}$ Carston believes that in general the logical form cannot be equated with a full proposition, but we may concede that in a number of cases a minimal proposition is projected by a logical form.
} 
meaning attributed to the linguistic element triggering the presupposition or the meaning of the utterance carrying the presupposition. In particular, we consider presupposition from a pragmatic perspective, namely we regard it as what the speaker assumes to be true, or rather, to be accepted by the interlocutor (Kempson 1975: 54; Kecskes and Zhang 2013). To presuppose a proposition is "to take its truth for granted, and to assume that others involved in the context do the same" (Stalnaker 1970: 279, 1974: 472). On this pragmatic perspective, a proposition $p$ is presupposed when it is taken for granted by a person in performing a speech act, whose felicity, or conversational acceptability (Stalnaker 1974: 473) depends on the interlocutor's acceptance of $p$ (Stalnaker 2002: 701). This act of subordinating the felicity of a speech act to the acceptance of its presuppositions (Allan 2013) can be considered as an act (Stalnaker 1973: 451), which results in turning the problem of presupposition cancellation into a dynamic problem of interpretation (Simons 2013; Kecskes and Zhang 2013). The issue of establishing the presuppositions of an act becomes essentially related to the problem of explicating what speech act is being performed, what its meaning is, and how to interpret the potential linguistic triggers of a presupposition. On this view, presupposition can be regarded as a condition, an element that needs to be taken into account for determining the utterance meaning of a sentence used in a specific context (Katz and Langendoen 1976: 15).

\section{Presupposition and Explicatures}

According to Stalnaker (1974), semantic presuppositions are encoded in the semantic structures of sentences, while pragmatic presuppositions are propositions that the speaker of an utterance takes for granted, namely as following from the common ground of shared information (Abusch 2002). The relationship between these two levels of presupposition is complex, as semantic presuppositions can be projected or suspended depending on several pragmatic factors. However, this distinction can be read as drawing a crucial distinction between the default meaning and the actual uses of linguistic elements in performing an utterance. On this perspective, the problem of presupposition inheritance and suspension becomes rather a problem concerning the relationship between default meanings and conscious pragmatic inference aimed at reconstructing the meaning of an utterance.

From a pragmatic point of view, the defaultive use of a predicate needs to be distinguished from its actual one. The semantic components constituting the definition of a predicate can be used pragmatically in different fashions. For example, the predicate "bachelor" can be used defaultively in "My neighbor is a bachelor" to assert that the male human being living close to the speaker's house is not married. However, different semantic components can be taken for granted, depending on the context and, more precisely, what can be considered as shared (Gundel and Fretheim 2004). For example, the aforementioned sentence can be 
used in a context in which the sex of the neighbor is uncertain, and in this case the fact of his being unmarried is left in the background (Langendoen and Savin 1971: 342). This idea was expressed in the Middle Ages with the notion of pragmatic ambiguity: a predicate having a unique meaning (a specific definition representing the presumptive meaning) was regarded as being (pragmatically) ambiguous when it was used equivocally to express a different predicate (Abealardi Dialectica, 568). This distinction can be interpreted as a differentiation between the univocal presumptive meaning (corresponding to the sentence type) and its possible nonpresumptive uses (the utterance meaning) (Katz and Langendoen 1976: 10). Our proposal consists in trying to explain the relationship between the sentence and utterance presuppositions, and the problem of presupposition projection in terms of explicatures.

We consider the following cases:

1. Maria ha smesso di fumare.

(Mary has stopped smoking (this specific cigarette or in general)).

2. Mary regretted studying medicine (when she was taking a difficult test of medicine).

The first two cases show how the absence of a context can affect the interpretation of an utterance. "To stop (an action)" only presupposes that the action started some time before the utterance time, and that it is a process (I cannot say "*I stopped dying" or "*I stopped going to Paris last Saturday") or a repetitive occurrence ("I stopped sneezing"). This ambiguity is extremely evident in Italian, where the expression commonly used to indicate the interruption of a habitual activity is frequently used to refer to the interruption of a specific action (Ha già finito di fumare? - Has he stopped smoking (his cigarette - yet?). Similarly, "to regret" presupposes an event or state of affairs and the agent's action in bringing about the state of affairs (Rorty 1980: 490). However, the presumptive reading leads us to interpreting (1) as a habit, and not as a specific action, and (2) as a completed negative action, and not as a decision to engage in the action. In both cases, the presumptive reading (the repetitive performance of an action; an action as a completed event) is different from the non-presumptive one. In (1) the action is regarded as an occurrence, while in (2) it is interpreted as a process engaged in by a specific agent at a specific time, upon a specific decision, and with a specific duration.

\section{Explicating Non-presumptive Meaning}

The treatment of presuppositions in terms of the predicates that are represented by the expression used in an utterance directly links the issue of presupposition and interpretation to the problem of explicatures. As Huang (2007: 32) maintains: 
[...] conversational implicatures are characterized by a number of distinctive properties

[...]. In the first place there is defeasibility or cancellability: conversational implicatures can simply disappear in certain linguistic or non-linguistic contexts. How? They are cancelled if they are inconsistent with (i) semantic entailments, (ii) background assumptions, (iii) contexts, and/or (iv) priority conversational implicatures.

Since explicatures are calculated on the basis of pragmatic inference, we could prima facie think that explicatures too are cancellable. However, the application of the notion of cancellability to explicature turns out to be problematic (Capone 2009). The main problem is that explicatures usually have a function that goes beyond that of implicatures: making a segment of discourse coherent and logical (e.g. rescuing it from contradiction), and thus projecting speaker's strong intentions. Without an explicature some utterances result in implausible, absurd interpretation (sometimes even patent falsehood results). Moreover, explicatures are based on several discourse clues, which are aimed at projecting the speaker's intention and making its accessible to the hearer. For this reason, the cancellation of an explicature would result in the cancellation of such clues - which once disseminated cannot be deleted $^{3}$ (Capone 2009).

On this perspective, the implicit assumptions that constitute the explicit meaning of an utterance are also essential elements for the reconstruction of the nonpresumptive meaning of an expression. For example, in order to interpret (1) above as referring to an action instead of (presumptively) a habit, the tacit elements of meaning constituting such an action or predicate need to be reconstructed as follows:

1'. Mary has stopped (the action of) smoking (a cigarette).

Now consider the following example, which is very interesting because it shows that presupposition is connected with the pragmatic process of construction of an explicature:

\section{I have stopped smoking before I even started.}

In (3), an apparent contradiction or inconsistency arises. However, the communicative intention can be "saved" by resorting to an interpretation of the utterance that is not the presumptive one. In this case, the utterance can be interpreted by regarding the agent as not simply discontinuing an action, but rather a repetition of actions leading to a habit. The explicature can bring to light the underlying assumptions needed to retrieve such an interpretation:

$3^{\prime}$. I have stopped (the process leading to the habit of) smoking before I even started (to be involved in such a habit).

\footnotetext{
${ }^{3}$ An explicature concerns the specific logical form of the proposition expressed by an utterance within a specific context. In this sense, an utterance takenout-of-context can be enriched only potentially with explicatures (Capone 2009). The potential explicature of (1): "Today it is raining" is "It is raining [HERE];" however, this explicature does not conflict with $\left(1^{*}\right)$ :"Today it is raining, but not here." ( $\left.1^{*}\right)$ is simply a different utterance, and is perfectly consistent with an interpretation in which there is no explicature and thus "but not here" does not cancel anything.
} 
(3) could be interpreted as meaning that the speaker was close to yielding to the temptation of starting smoking but she stopped smoking in the sense of aborting that intention. Should there be at least an event of smoking before stopping? Is an intention to smoke part of the event of smoking? Certainly there cannot be an event of smoking without the intention. ${ }^{4}$ The event, furthermore, can be imagined to occur after the intention is formed. So in a sense the speaker came close to the event of smoking but he stopped in time. Even though it is controversial, we need to underscore that the admittedly out of the ordinary utterance "I stopped smoking before I even started" challenges the cogency of the logical approach to presupposition.

The relationship between explicatures and presuppositions becomes clear when the interpretation of an utterance and the presuppositions underlying it depend on background assumptions. For example we consider the following case:

\section{Giovanni, non aiutare questo giornale.}

John, do not support this journal.

The presumptive reading of this statement (not involving any presupposition) can become problematic when it conflicts with the background assumption that the hearer is known to support the journal. In this case, a different reading is necessary: instead of asking not to perform an action, the speaker is asking of interrupting a habit. The first interpretation does not involve any presupposition, while the second one can be reconstructed as follows:

4'. John (since you used to support the volume), do not to support the journal (any longer).

The explicature ("any longer") reveals a presuppositional and non-presumptive reading that can be retrieved only considering the background assumptions shared by the interlocutors.

Clearly, if we treat predicates and sentences in terms of presumptive meaning, explicatures become essential elements for reconstructing a non-presumptive meaning of a term. Explicatures, inasmuch as they represent the communicative intention, cannot be cancelled. Capone maintained that strong intentionality cannot be retracted, and since an explicature is necessary to sustain the rationality of the speaker, it cannot be cancelled (Capone 2009; 2013a, b). The problem of presupposition becomes, in this sense, a problem of explicature and explication of meaning, especially for those cases where the alleged presupposition rests on an explicature, which is impossible to cancel.

\footnotetext{
${ }^{4}$ As an extreme case, I could think of someone who is compelled to smoke, without his having such an intention; however, since he does not have this intention, he cannot stop smoking: as soon as the cigarette is pulled out of his mouth, he is no longer smoking, which is different from stopping smoking a cigarette.
} 


\section{Explicatures and Meta-linguistic Negations in Presupposition Suspension}

Non-presumptive meaning, as mentioned above, is strictly related with the explication of the components of a predicate that are brought to the foreground and left in the background. Our claim is that the pragmatic dimension of presupposition should be interpreted in terms of polyphony. This account could provide an understanding of the mechanism of "presupposition inheritance" and of the more complex cases in which the semantic presupposition is not projected.

A crucial case of presupposition cancellation involves the meta-linguistic negation of the content or part of the content expressed by an utterer. By performing this negation, the speaker does not commit himself to what an utterer said. For example we consider the following cases:

5. The reason he stopped loving you is because he never really loved you in the first place. ${ }^{5}$

6. So she stopped smoking, because she never smoked before. She said to herself - "I am a non- smoker. I have never smoked. I don't know how to hold a cigarette." 6

7. I regret doing it even though I have never done it (I don't remember it).

Unlikely the first two cases, (5), (6), and (7) are cases of apparently infelicitous or even inconsistent or contradictory utterances. However, it is possible to resort to an interpretation of such utterances that can reconstruct the intended communicative intention of the speaker. The speaker can be presumed not to rely on the presumptive or default meaning of the predicates "to stop" and "to regret," and to have relied on the interlocutor's understanding that a process of non-defaultive meaning reconstruction was required. In these examples, the presupposition of "to stop" and "to regret" is suspended, because it is contradicted by the subsequent explanation. In such cases, the allegations of committing the actions that have been stopped or regretted are quoted and meta-linguistically negated. Such cases can be explained by using the idea of polyphony, which certainly interacts with the notion of pragmatic presupposition through the notion of speaker's commitment.

As pointed out above, an expression can be used not to represent a state of affairs, but rather a linguistic element ("to stop" is a verb), a part of an utterance (I have not "stopped" but rather ended the relationship), or a dimension of a reported state of affairs (I have not "stopped" smoking, I have never begun) (see Simons 2006: 5).

\footnotetext{
${ }^{5}$ Retrieved from: http://sequentialcrush.blogspot.pt/2013/04/i-know-you-are-dying-to-knowtruth.html

${ }^{6}$ Adapted from: https://books.google.pt/books?id=4kq1qgBBsMIC\&pg=PA179\&lpg=PA179\& $\mathrm{dq}=\% 22$ she+stopped++smoking $\% 22+$ never+smoked\&source=bl\&ots $=2 \mathrm{C}-$ he $54 \mathrm{RdO} \&$ sig $=$ s4HGi1ShomltgFhY2ZZ7yRNK_MA\&hl=it\&sa=X\&ei=zs8GVZf6E4HkUJi6g9AE\&ved= 0 CEEQ6AEwBQ\# $\mathrm{v}=$ onepage $\& \mathrm{q}=\% 22$ she $\% 20$ stopped $\% 20 \% 20$ smoking $\% 22 \% 20$ never $\% 20$ smoked \&f=false
} 
In this sense, the meta-linguistic meaning of an expression corresponds to indirect report (see Burton-Roberts 1989; Carston 1996: 334), such as in the sentences above. For example we consider (5):

5'. The reason he stopped (the action that you indicated as) (")loving you(") is because he never really loved you in the first place

In (5'), the explicature makes it explicit that the utterance reported belongs to an utterer different from the speaker and underscores that the verb "to stop" was used infelicitously, given the mistaken presupposition (see a similar treatment in Sperber and Wilson 1986: 242). The treatment of (6) is more complex, as it involves a voice reporting what the agent says, and another indicating what the agent thinks:

6'. So she (said that she) (")stopped(") smoking (even though it is incorrect saying it), because she (convinced herself that she) never smoked before.

In this case, the explicature introduces a distinction between two voices, the one of the utterer reporting that the agent used the term "stopping of smoking" in an allegedly wrong way, and the other of the utterer expressing the conviction of having never smoked. Case (7) involves two distinct voices, belonging to the same physical person:

7'. I (say that I) (")regret(") doing it even though (I am not convinced of it because)I have never done it.

Here two voices are distinguished, the one uttering that the agent regrets his action and that he has never done it, and the other expressing what the utterer is contradicting, namely the fact that he committed the regretted action.

In all three cases, voices are distinguished at different levels, introducing different linguistic agents responsible for different parts of the discourse (see Beaver 2010: 22). In (5) and (7) the voices are related to a meta-linguistic use of a predicate, while in (6) to different epistemic statuses of the utterer. This distinction can be used to explain more complex cases in which the apparent presupposition projection failure is not explained through meta-linguistic negations.

\section{Polyphony and Presupposition Suspension}

Certain cases of presupposition suspension involving meta-linguistic negations can be treated as explicatures bringing to light indirect reports, namely voices advancing contents to which the speaker refuses to commit. This analysis can be extended to several other presuppositional phenomena. The foundation of this approach consists in applying to the analysis of presuppositions the plurality of characters responsible for a specific linguistic act.

In his linguistic theory of polyphony, Ducrot distinguishes in an utterance different voices, or rather various points of view that are brought forward by distinct 
utterers. Such perspectives can be considered as pragmatically different because the linguistic character that is responsible for the utterance, the speaker, takes the responsibility only for some of the contents, namely the one that is asserted (posé) by one of the utterers, but not for the one that the utterer presents as representing a collective voice (the presupposed content). For example, we consider (1) above:

\section{Mary has stopped smoking.}

In (1), Ducrot distinguishes the asserted content (posé), and the presupposed one (présupposé). The speaker (locuteur), the linguistic character responsible for taking charge of the utterance (Ducrot 1984: 179), is differentiated from the utterers (énonciateurs), the "voices" responsible for (or rather the perspectives presented as) the contents that have been asserted and presupposed ${ }^{7}$ (Beaver 2010: 22). In (1), a first utterer (Ducrot calls him Énonciateur 1) is responsible for what is asserted, while a collective voice or a second utterer (an $O N$ as Ducrot calls it), to which the speaker belongs, is responsible for the presupposition (Ducrot 1980: 83, 1984: 231-233). According to Ducrot, the speaker takes on the responsibility, or the perspective, of the first utterer, but not the one of the content uttered by the second, collective voice, which performs the act of uttering the content that is so presupposed (Ducrot 1984: 172). In this sense, the presupposition can be considered to be an act (even though a non-assertion, Abbott 2000), consisting in the utterance of a statement by a different utterer, and not resulting directly in the speaker's taking responsibility for it (Ducrot 1984: 190).

Ducrot's theory of polyphony can be interpreted from an argumentative and dialectical perspective (Hamblin 1970; Walton and Krabbe 1995).The pragmatic concept of "taking the responsibility for" an utterance (or specific perspectives) can be analyzed in terms of dialectical obligations or commitments. Hamblin (1970: 257) defined commitment by means of a set of statements that a participant in a dialogue (a purely dialectical role within a dialogue game) is obliged to maintain consistently or retract. On this view, the linguistic character of the speaker can be interpreted as a dialectical role (the proponent, as opposed to the interlocutor or respondent), who is committed to (in the sense of taking the dialectical responsibility for) the contents that are posé. The contents that are présupposé can be said to belong to or be inserted into a set of commitments that Walton and Krabbe defines as "dark-side" (1995: 12). Such dark-side commitments represent what is taken for

\footnotetext{
7“Je signalerai enfin une perspective particulièrement prometteuse qui s'ouvre dès qu'on considère le sens comme un représentation de l'énonciation, représentation consistant notamment à y faire entendre la voix de divers énonciateurs s'adressant à divers destinataires et à identifier ces rôles illocutionnaires avec des personnages qui peuvent être, entre autres, ceux de l'énonciation. Il s'agit de la construction, dans le discours, du locuteur et de l'allocutaire. Psycho- et socio-linguistes ont quelquefois noté [ ... ] que l'on peut, en parlant, constituer une image de soi et de la personne à qui l'on parle, image que l'interlocuteur tantôt accepte et tantôt rejette. Un des principaux moyens de cette constitution est justement la possibilité, inscrite selon nous dans la langue, c'est-à-dire dans la signification des mots et des phrases, de faire s'exprimer différentes voix, en donnant l'instruction de les identifier à des êtres de la réalité -et en spécifiant même certaines contraintes à observer dans cette identification" (Ducrot 1980: 56).
} 
granted, and both the proponent and the respondent are or become committed to upon the performance of a speech act presupposing a specific content. In this sense, the voices of the utterers proposing distinct pragmatic perspectives can be thought of as corresponding, in a dialectical perspective, to various types of commitments, whether light-side or dark-side.

Polyphony and the consequent treatment of presupposition as an explicature of the different linguistic agents responsible for the various statements allows one to understand the aforementioned mechanism of explicatures needed to explain presupposition suspension. This account can be also applied to more complex constructions, such as the following ones:

8. If Mary had stopped smoking, she would be alive now.

9. It is possible that Mary has stopped smoking (or that she never has).

10. If you stopped smoking in 2001, you are eligible for a payment from the Tobacco Indemnity Fund (Abusch 2002: 2)

11. If I discover that Mary is now in New York, I will be angry (Abusch 2002: 2).

In (8) the first utterer, corresponding to the speaker, is responsible for the conditional (in this case a counterfactual, i.e. the truth of the connector "if . . then"), whereas the second utterer, the common opinion, is attributed the responsibility of the factual presuppositions that Mary smoked, that she did not stop it, and that she is not alive. The only non-metalinguistic negation of (8) would be to show that Mary would not be alive in case she stopped smoking. All the other negations ("but May never smoked;" "but Mary is alive") correspond to the meta-linguistic negations, which can be regarded as negations of the felicity of an utterance.

The treatment of (9) is similar. The first utterer is responsible for the truth of the disjunction, to which the speaker is committed explicitly; this, however, simply hides the presupposition of which the second utterer is responsible:

9'. It is possible that Mary(is not doing anymore what the second utterer/everybody say that she used to do, i.e. smoking) or that she has never smoked.

The different voices emerge when the one of the members of the disjunction is denied:

9". (the first utterer did not say felicitously that) Mary has (")stopped(") smoking, then/because (it is true the contrary of what thesecond utterer/everybody said, i.e.) she has never smoked.

(10) and (11) are more complex cases, because they allow two distinct interpretations, one in which the presuppositions of "to stop" and "to discover" are projected, and the other in which they are suspended. In such cases, there is a difference in interpretation due to background assumptions (Abrusán 2011: 492; Beaver 2010). In the first interpretation of (10) (uttered by a friend to another, knowing that the latter used to smoke), the speaker corresponds to the utterer who is committed to the truth of the conditional,while a second utterer (the common opinion) is committed 
to truth of the presupposition ("You used to smoke before 2001"). It is possible to make the polyphony explicit using the following explicatures:

10(a). If (it is true that) you stopped smoking (since you used to smoke before 2001, as everyone/the second utterer says) in 2001, you are eligible for a payment from the Tobacco Indemnity Fund.

In this case, the negation can have as a scope both the asserted content and the presupposed one (I never stopped smoking because the second utterer was wrong in saying that I used to smoke). The second reading is more complex:

10(b). If (it is true that) you (performed the action of) ("stopping) smoking before 2001("), you are eligible for a payment from the Tobacco Indemnity Fund.

In this case, the utterance concentrates on the action as a whole, not on the activity that has stopped. However, the presupposition emerges again in case of the negation of the antecedent (I have not stopped smoking before 2001, as I have never smoked before):

10(c). (The first utterer did not felicitously say that) I have "stopped" smoking (as the second utterer was wrong in saying that I smoked before 2001).

The same analysis can be applied to (11), which also has a presuppositional and non-presuppositional reading.

11(a). If (it is true that) I discover (the fact that is reported by the second utterer/everyone) that Mary is now in New York, I will be angry.

11(b). If (the event consisting in that) (")I discover that Mary is now in New York(") (is true), I will be angry.

As in 10 above, also in 10 the two readings correspond to a polyphonic and nonpolyphonic interpretation. The presupposition is projected when the conditional has a polyphonic structure; when there is no such polyphonic structure (as I only concentrate on my discovery of Mary's being in New York), the presupposition is not projected, as the utterer is only committed to the expressing the possibility of an action (see Beaver 2010: 28). The same polyphonic treatment can account for the different projections of presupposition with other triggers (see Abrusán 2011: 523). By determining the scope of the predicateit is possible to reconstruct the commitment structure.

The same analysis can also explain the difference of the presuppositions projected by hard triggers, such as "too":

11(c). If (it is true that) I discover (the fact that is reported by the second utterer/everyone) that Mary is now in New York too (in addition to someone else, as reported by the second utterer/everyone), I will be angry.

11(d). If (the event consisting in that) I discover (the fact that is reported by the second utterer/everyone) that Mary is now in New York too (in addition to other facts, as reported by the second utterer/everyone), I will be angry. 
In this case, the scope of the trigger can be on Mary (11c) or on the event (11d), resulting in different presuppositions. Clearly, it is possible to place a pragmatic stress on "too" and suspend the presupposition:

11(e). If (it is true that) I discover (the fact that is reported by the second utterer/everyone) that Mary is now in New York TOO (in addition to someone else), I will be angry.

In this case, the speaker can have meant that the problem is indeed the presence of someone else with Mary in New York that causes the problem (Marmor 2008: 443). The polyphonic structure of the statement reveals what is attributed to the common voice and what the first utterer is responsible for, bringing to light what is left in the background.

This treatment of presupposition, conceived as a commitment undertaken by an utterer different from the one responsible for the asserted content (see Simons 2013: 332 ), can lead to a complex pragmatic analysis of specific constructions involving verbs of belief or indicating internal epistemic states.

Similar examples can be multiplied. Consider the following situation:

Today I was walking on a sidewalk and suddenly I saw many (shattered) pieces of glass. Another passerby commented aloud that there were many pieces of glass. A friend of his replies: "Then we can no longer walk bare-footed" (translation from Italian).

This example is very interesting from the point of view of polyphony. The remark 'Then we can no longer walk barefooted' has to be considered ironical - one knows well that in Italy one cannot walk bare-footed because there may be nails, pieces of glass, pebbles, etc. on the pavement. Thus, the presupposition 'we used to walk bare-footed', triggered by the habitual reading denier 'no longer' is suspended as it happens to be situated in the context of an ironical utterance. The presupposition is projected indeed, but it inherits the features of the ironical utterance in which it is embedded and thus has to be intended in an ironical way as well. This shows that presupposition (even in positive sentences) is a really and genuinely pragmatic notion, one that needs to depend on the interpretation of the utterance.

\section{Explicatures and Presuppositions of Epistemic States}

This polyphonic approach based on explicatures shifts the analysis of the presuppositions from the epistemic objective level of truth to the dialogical one of commitment. A presupposition is not cancelled; rather, the use of the predicate triggering it can be contested. In this sense, the cases of presupposition cancellation can be explained in two different ways, depending on the structure of the commitments of the distinct linguistic agents. A presupposition can be "cancelled" in the sense that the felicity of the utterer's move is challenged, due to an infelicitous use of the predicate presupposing a proposition unacceptable for or unaccepted by the speaker. Otherwise, a proposition can be attributed to two different utterers, one asserting it and the other presupposing it, such as in cases above. In this case, the presupposition is apparently cancelled, as the first utterer, corresponding to the speaker, asserts it 
in one of the members of the disjunction or the conditional. However, when the members of the complex proposition triggering the presupposition are denied, the negation either entails or corresponds to a meta-linguistic negation.

Polyphony becomes crucial for explaining presuppositions in verbs indicating epistemic states (Capone 2001), and in particular emotive factives (Abrusan 2011: 514). We consider the following cases:

12. John said that Mary has to stop smoking, but she never smoked before.

13. John said that Mary regrets going to Rome with Mark, but she never actually went there.

It is common opinion that "stop" and "regret" are presuppositional triggers. The embedding within indirect reports does not normally suspend the presuppositions, which are inherited by the complete utterance (through conversational implicature, presumably). However, there is nothing in the semantics of these two verbs that can guarantee that the presuppositions will survive. In these cases, the first utterer (coinciding with the speaker), responsible for the whole utterance, is distinguished from John, who is committed to the proposition that "Mary has to stop smoking" (or "Mary regrets going to Rome with Mark") while a third utterer is responsible for the presupposition ("Mary smoked"; "Mary went to Rome with Mark"). The first utterer, however, comments on the felicity of John's utterance by challenging the presupposition. The meta-linguistic challenge of the felicity of John's speech acts in case 12 and 13 results also in a challenge on the acceptability of the speech act of presupposing made by the third utterer. There is a clear asymmetry between case 12 and case 13 above. In 12, the speaker (first utterer) challenges John's statement and the presupposed content for which a third utterer is responsible. The failure to challenge the statement would result in the speaker's accepting the presupposition. Case 13 is different, as Mary is also committed to the presupposed content. In a certain sense, the two following statements are similar:

14. Mary regrets going to Rome.

15. Mary believes she went to Rome, and she is sorry about that.

In the same way in which we cannot have direct access to Mary's mind and beliefs, with the exception of cases in which we share mutual knowledge (perception of the environment), we cannot have access to Mary's regrets. Such regrets are like her beliefs. These beliefs can be explicated by resorting to indirect reports (May 1987):

14'. (the first utterer says that the third utterer and) Mary (believe that Mary went) to Rome (and Mary is sorry that she went to Rome).

For this reason, 13 can be reconstructed relying on the following explicatures, bringing to light the polyphony and the contents attributed to the distinct utterers:

13'. (the utterer called) John said that (the second utterer called) Mary regrets going Rome with Mark (and the third utterer/common opinion, with which Mary agrees, says that she went to Rome with Mark), but (Mary did not say felicitously that she "regrets" because) she never actually went there (contrary to what the second utterer believes). 
But at this point, given the explicature, it is no longer useful to say that "to regret" entails the embedded constituent. Rather, the structure of this verb can be reconstructed through the commitments resulting from its use. The first utterer/the speaker can simply report Mary's regretting her going to Rome, and in this case he does not take any epistemic position about the proposition for which Mary and the third utterer are responsible. Otherwise, he can challenge meta-linguistically the use of the predicate "to regret" and in this fashion he points out that he is not committed to the proposition that is attributed to the voices of Mary and the third utterer.

From a dialectical perspective, this reconstruction allows one to calculate the possible effects of a speech act on the interlocutor's commitments. If the acceptability of an embedded constituent (the proposition regretted in this case) is not challenged by questioning the felicity of the speech act, the presupposition is inserted also into the interlocutor's commitments, as he is part of the community represented by the third utterer. If the speaker challenges the use of the embedding predicate, he prevents the presupposed proposition from being part of his own and the interlocutor's commitments. This account can explain the presuppositional effects triggered by extraposition to the right in Italian (Capone 2000; for the problem of extraposition and presupposition, see Gundel and Fretheim 2004; Hockett 1950; Green 1996: 74; Capone 2013a, b). For example we compare the following:

16. John knows that Mary is in Paris.

17. John knows that Mary is in Paris. But Mary is in London.

18. John lo sa che Maria è a Parigi. (*But Mary is in London).

(Lit. John it knows that Mary is in Paris, equivalent to the English "John knows it, that Mary is in Paris", or John KNOWS that Mary is in Paris)

While (16) presupposes that "Mary is in Paris," in (17) the presupposition is suspended. However, the extraposition to the right, marked by the expletive "it" (Kim and Sag 2005), in (18) makes the suspension impossible (see Abrusán 2011: 527). If we reconstruct the explicatures underlying these three statements, we can bring the implicit polyphony to light:

16'. (the first utterer says that) (the second utterer called) John (says that he believes) that Mary is in Paris (and the third utterer/the common opinion says that is true that Mary is in Paris).

17'. (the first utterer says that) (the second utterer called) John (says that he believes) that Mary is in Paris (and the second utterer says that it is true that Mary is in Paris). But (the first utterer says that) Mary is in London.

18'. (the first utterer says that) (the second utterer called) John (believes) it (what the third utterer says that is true, and the first utterer agrees with), that Mary is in Paris.

The responsibility of the first utterer for the presupposition, i.e. the "dark-side commitment," is indirect and implicit in (16). Here, his agreement with the common opinion is a presumption that is automatically triggered, but that can be denied without incurring a contradiction. In this sense, (16) is potentially ambiguous from a polyphonic point of view, as it can be interpreted as indirectly reporting an 
epistemic status of knowledge (embedding a proposition to whose truth the speaker is committed) or one of belief (not entailing this commitment). For this reason, (16) can be explicated both as (16') or as the first conjunct of (17'). However, the expletive "it" in (18) rules out the possibility of interpreting (16) as (17'), as it includes the in the speaker's (corresponding to the first utterer's) commitments the truth of the proposition known by the second utterer. For this reason, the extraposition, by clarifying the polyphonic reading of the statement, disambiguates the potential ambiguity of the Italian "sapere," which can be explicated presumptively as "to know" or non-presumptively as "to believe." 8 The expletive "it" stabilizes the presumptive reading. ${ }^{9}$

The issue of verbs of knowledge in different languages is very interesting from the point of view of the presuppositions. Although we cannot deepen this issue from an intercultural pragmatics perspective, we should at least mention that another article should be written on intercultural differences. What happens when an English-speaker is faced with Italian data or an Italian speaker is faced with English data? Presumably, if the conversationalists notice some discrepancy between their languages, they can discuss it and the upshot of that discussion can be taken as an emergent presupposition in the sense of Kecskes (2013). Emergent presuppositions, according to important insights due to Kecskes, are the basis for the development of conversation in intercultural situations. ${ }^{10}$ This issue, however, cannot be addressed here.

\footnotetext{
${ }^{8}$ This non-presumptive reasoning can be also interpreted as a case of a parasitic use. The use is tolerated, despite the fact that it is ungrammatical. Yet Italians, in informal speech, do not perceive it as ungrammatical. Certainly there is ambivalence in usage and it is possible that in some contexts stronger meanings are accessed, while in other contexts (especially the least formal ones) the weaker meanings prevail. However, even on the TV programs and the news the weaker forms of "sapere" are attested. They are certainly used in a sense that is different from that of the English verb "to know." Although the philosophical literature attests the use of "John knows that $p$ but not $p$," it only concedes that this is a parasitic, tolerated but ungrammatical usage.

${ }^{9}$ The Italian clitics tend to implicate that a proposition embedded in "sapere" (but also in other verbs such as "sentire," "capire," "immaginare," "dire") is true or anyway accepted by the speaker (and shared with the hearer). These seem to us to be uncontroversial cases where a presupposition is conversationally implicated. Now, apart from the case of "sapere," where the presupposition is entailed and implicated (in the sense that loose, parasitic or weaker uses of "sapere" are excluded, since factivity is strongly implied), the other verbs mentioned (in Italian) do not seem to entail the truth of the embedded proposition. Thus a definitive result has been achieved for Italian, where the notion of presupposition seems to intersect with the notion of conversational implicature. Here the further problem that clitics usually tend to promote strong factive readings through inferences that appear to be not cancellable is resolved thanks to Capone's previous considerations on the cancellability of explicatures/implicatures, not to mention the fact that contextual variation can prove that we are faced with conversational implicatures (See Capone 2000 and Capone 2013b on verbs of propositional attitude combined with pronominal clitics).

${ }^{10}$ As Kecskes (Forthcoming) says, "Commonalities, conventions, common beliefs, shared knowledge and the like all create a core common ground, a kind of collective salience on which intention and cooperation-based pragmatics is built. However, when this core common ground appears to be mostly missing or limited as is the case in intercultural communication interlocutors cannot take them for granted, rather they need to co-construct them, at least temporarily."
} 


\section{Presuppositions and Explicatures of Illocutionary Forces}

In the sections above we took into account utterances whose illocutionary (and perlocutionary) force was reconstructed presumptively. In some cases the assignation of illocutionary and perlocutionary forces to utterances can be controversial (Kissine 2012) and the presumptive interpretation is subject to default. Also in such cases the phenomenon of presupposition suspension can be explained resorting to the explicatures that provide the background assumptions and the enrichment resulting in the actual attribution of the illocutionary force to the utterance.

Some presupposition suspension cases derive from the prototypical relationship between sentence-types and illocutionary forces. Declarative sentences are usually interpreted as used to perform assertive speech acts (Sperber and Wilson 1998: 268), just like expressive sentences are habitually used to perform expressive speech acts. However, this presumption is often subject to default, like in indirect speech acts (Capone 2010a), especially the ones that are not conventionalized and whose interpretation needs to be retrieved. The interpretation of an utterance as a speech act clearly affects the structure of the presumptions associated thereto. For example, we consider the following cases:

\section{9. < Said by a professor to a student that has not returned yet a book borrowed}

from the professor $>$ Many thanks for sending the book.

20. Ti ringrazio anticipatamente (Many thanks in advance for ... ). ${ }^{11}$

21. <On a sign posted in a restaurant $>$ Thank you for not smoking.

These statements can be interpreted presumptively as acts aimed at expressing gratitude for an action performed by the interlocutor. "To thank for" presupposes a reason, which needs to be a voluntary action, positive for the utterer, performed by the hearer. For this reason, such statements can be interpreted presumptively as presupposing (Allan 2013) that the hearer has sent the book, and that the people in the premises have not smoked. However, such interpretations are subject to default (see Kecskes and Zhang 2013: 383-384 for the treatment of presuppositions used to inform). In the context in which the book has not been sent yet, the utterance expresses a kind invitation ("Please send me the book"), while the sign also expresses a kind order to the customers entering the premises ("Please do not smoke"). In such cases, the presumptive interpretation is subject to default because the requirements of the presumed speech act of thanking are not complied with (Ducrot 1966: 42; Macagno 2012a, b). In this case, a more complex process of explanation is triggered, in which the communicative intention is reconstructed in

\footnotetext{
${ }^{11}$ We would like to thank Dorota Zielińska who suggested us examples 19 and 20. See Zielinska 2013.
} 
order to avoid a communicative failure. The presumptively presupposed content becomes the ordered one:

19'. (Send me the book, and) many thanks (if you decide to send the book).

20'. Many thanks for (the action that I have told you to perform and that you will perform).

21'. (Do not smoke, and) Thank you (if you decide not to smoke).

The speaker is thanking the hearer for a future hypothetical decision that is presupposed by an implicit order. The speaker is taking for granted that a specific conduct has been requested, which opens up the possibility of complying or not complying with it. We represent the process of explaining the non-presumptive illocutionary force as follows (Fig. 1):

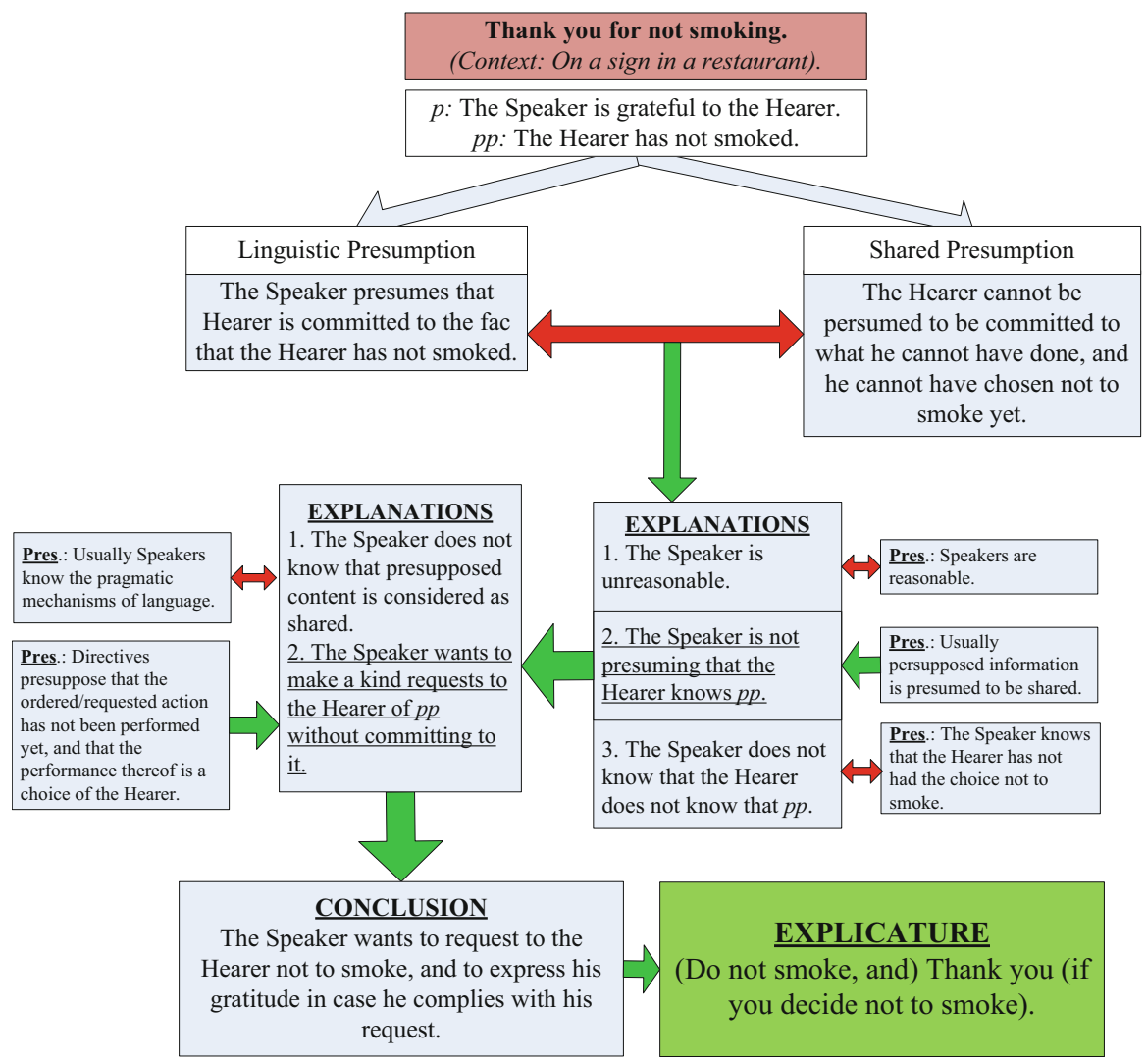

Fig. 1 Reconstructing the explicature of a speech act 
In this figure, the reconstruction of the explicature of the speech act is represented through a process of reasoning in which the linguistic and epistemic presumptions are compared and analyzed. The Speaker's move, presumptively interpreted as an act of expressing gratitude for a Hearer's action, conflicts with the presumptions associated with the shared communicative situation (for the notion of presumptions and common ground, see Kecskes and Zhang 2009) and the Hearer's possible knowledge. The Hearer cannot be presumed to share a proposition that he cannot know, as it cannot have happened yet (Macagno and Walton 2014:chapter 5; Macagno 2012a, b). For this reason, the apparent unreasonableness of the communicative move leads to a default of the presumptive interpretation, and an alternative one is reconstructed (see Simons 2013: 17). Since the Hearer is not presumed to accept the action presupposed by the verb "to thank" (namely to accommodate the necessary presuppositions, see Simons 2006: 13), the possible explanation is that this verb presupposes a possible future decision. Since the decision not to smoke was not subject matter of the Hearer's consideration, the act presupposes a previous act of displaying a choice, in this case between smoking and not smoking. The act that brings about this effect on the Hearer's behavior is a directive, in this case a request (for the interplay between the sentence level and the interpretation of the illocutionary force of a speech act, see Capone 2005; see also Jaszczolt 2005, 2010).

\section{Conclusion}

Presupposition projection and suspension, and the complex relationship between the semantic triggers and pragmatic presuppositions can be explained as the indications of a complex phenomenon of non-presumptive interpretation. Linguistic elements, such as verbs or syntactic constructions, and utterances are usually interpreted presumptively as bearing the prototypical meaning (or illocutionary force). This relationship is only presumptive in nature, subject to default in case new information, in this case co-textual or contextual in nature, comes in. The suspension of a presupposition commonly associated with the interpretation of a predicate or an illocutionary force can be explained as the trigger of a non-presumptive reading, in which the predicate or the utterance is interpreted in a non-automatic fashion.

Explicatures can bring to light the complex background-foreground articulation of information that characterizes the use of a sentence in a speech act. Specific components of the meaning of a predicate can be brought to the foreground, while others taken for granted. This distinction between the semantic components of a predicate and the use thereof in an utterance can explain why certain presuppositions are not projected. This articulation of information is essentially connected with the complex polyphony underlying a text. If we conceive discourse in pragmatic terms, we need to account for a crucial dimension of an action, the responsibility of the agent for what he performs. From a communicative point of view, a speaker can be held directly responsible for what is says, but only indirectly 
for what he presupposes (Ducrot 1984: 232-233; Walton and Krabbe 1995: 12). Presuppositions, in particular, are indirectly reported by the speaker, as they are attributed to a second voice, belonging to the community of speakers to which the hearer belongs. The suspension of a presupposition can be considered to be as the result of an act aimed at modifying the presumptive polyphonic structure of an utterance. The first utterer refuses to take responsibility for the presupposed proposition, and treats the presuppositional trigger as a quoted element of discourse, not resulting in any commitment for him.

The distinction between presumptive and non-presumptive interpretation of an utterance can explain also phenomena of presupposition suspension at the illocutionary level. On this view, the prototypical interpretation of a sentence-type is subject to default when one of its felicity conditions is not fulfilled. In this case, the presumption that the speaker intends to carry out a conversational effect is the strongest one that guides the reinterpretation of the utterance. By comparing the possible presumptions associated with the expressed meaning and the contextual information, the hearer can find a best possible explanation of the intended effect of the utterance. The reconstructed speech act in this sense corresponds to a nonpresumptive interpretation of an utterance, triggered and guided by the "suspension" of one the presuppositions of the habitual and prototypical reading.

\section{References}

Abbott, B. (2000). Presuppositions as nonassertions. Journal of Pragmatics, 32(10), 1419-1437.

Abrusán, M. (2011). Predicting the presuppositions of soft triggers. Linguistics and Philosophy, 34(6), 491-535.

Abusch, D. (2002). Lexical alternatives as a source of pragmatic presuppositions. Proceedings of SALT, 12, 1-19.

Allan, K. (2013). What is common ground? In A. Capone, F. Lo Piparo, \& M. Carapezza (Eds.), Perspectives in pragmatics, philosophy \& psychology volume 2 (pp. 285-310). Cham: Springer.

Atlas, J., \& Levinson, S. (1981). It-clefts, informativeness and logical form: Radical pragmatics (revised standard version). In P. Cole (Ed.), Radical pragmatics (pp. 1-62). New York: Academic.

Bakhtin, M. M. (1981). The dialogic imagination. (C. Emerson, M. Holquist, Trans.). Austin: University of Texas Press.

Bakhtin, M. M. (1986). Speech genres and other late essays (V. W. McGee, Trans.). Austin: University of Texas Press.

Beaver, D. (2010). Have you noticed that your belly button lint colour is related to the colour of your clothing. In Presuppositions and discourse: Essays offered to Hans Kamp (pp. 65-99). Philadelphia: Elsevier.

Burton-Roberts, N. (1989). On Horn's dilemma: Presupposition and negation. Journal of Linguistics, $25,95-125$.

Capone, A. (2000). Dilemmas and excogitations. An essay on modality, clitics and discourse. Messina: Armando Siciliano.

Capone, A. (2001). Modal adverbs and discourse. Pisa: ETS.

Capone, A. (2005). Pragmemes. Journal of Pragmatics, 37, 1355-1371.

Capone, A. (2006). On Grice's circle (a theory-internal problem in linguistic theories of the Gricean type). Journal of Pragmatics, 38, 645-669. 
Capone, A. (2009). Are explicatures cancellable? Toward a theory of the speaker's intentionality. Intercultural Pragmatics, 6(1), 55-83.

Capone, A. (2010a). On the social practice of indirect reports (further advances in the theory of pragmemes). Journal of Pragmatics, 42, 377-391.

Capone, A. (2010b). Barack Obama's South Carolina speech. Journal of Pragmatics, 42, 2964-2977.

Capone, A. (2013a). Explicatures are NOT cancellable. In A. Capone, F. Lo Piparo, \& M. Carapezza (Eds.), Perspectives on linguistic pragmatics, perspectives in pragmatics, philosophy \& psychology (2nd ed., pp. 131-151). Cham: Springer.

Capone, A. (2013b). The pragmatics of pronominal clitics and propositional attitudes. Intercultural Pragmatics, 10(3), 459-485.

Carston, R. (1996). Metalinguistic negation and echoic use. Journal of Pragmatics, 25(3), 309-330.

Carston, R. (2002). Thoughts and utterances. Oxford: Blackwell.

Ducrot, O. (1966). Le roi de France est sage. Implication logique et Présupposition linguistique. Etudes de linguistique appliquée, 4, 39-47.

Ducrot, O. (1980). Les mots du discours. Paris: Minuit.

Ducrot, O. (1984). Le dire et le dit. Paris: Minuit.

Green, G. (1996). Pragmatics and natural meaning understanding. New York: Erlbaum.

Grice, P. (1975). Logic and conversation. In P. Cole \& J. Morgan (Eds.), Syntax and semantics 3: Speech acts (pp. 41-58). New York: Academic.

Grice, P. (1989). Studies in the way of words. Cambridge: Harvard University Press.

Gundel, J., \& Fretheim, T. (2004). Topic and focus. In The handbook of pragmatics (pp 175-196). Oxford: Blackwell.

Hamblin, C. (1970). Fallacies. London: Methuen.

Heim, I. (1992). Presupposition projection and the semantics of attitude verbs. Journal of Semantics, 9(3), 183-221.

Hockett, C. (1950). Peiping morphophonemics. Language, 26, 63-85.

Huang, Y. (2007). Pragmatics. Oxford: OUP.

Jaszczolt, K. (2005). Default semantics: Foundations of a compositional theory of acts of communication. Oxford: OUP.

Jaszczolt, K. (2010). Default semantics. In B. Heine \& H. Narrog (Eds.), The Oxford Handbook of linguistic analysis. Oxford: OUP.

Katz, J. J., \& Langendoen, T. (1976). Pragmatics and presupposition. Language, 52, 1-17.

Kecskes, I. (2008). Dueling contexts: A dynamic model of meaning. Journal of Pragmatics, 40(3), 385-406.

Kecskes, I. (2013). Intercultural pragmatics. Oxford: OUP.

Kecskes, I. (Forthcoming). Can intercultural pragmatics bring some new insight into pragmatic theories? In J. L. Mey \& A. Capone (Eds.), Interdisciplinary studies in pragmatics, culture and society. Heidelberg: Springer.

Kecskes, I., \& Zhang, F. (2009). Activating, seeking, and creating common ground. A sociocognitive approach. Pragmatics \& Cognition, 17(2), 331-355.

Kecskes, I., \& Zhang, F. (2013). On the dynamic relations between common ground and presupposition. In A. Capone, F. Lo Piparo, \& M. Carapezza (Eds.), Perspectives on linguistic pragmatics, perspectives in pragmatics, philosophy \& psychology (2nd ed., pp. 375-395). Cham: Springer.

Kempson, R. (1975). Presupposition and the delimitation of semantics. Cambridge: Cambridge University Press.

Kim, J-B., \& Sag, I. (2005) Variations in English object-extraposition. In Proceedings of the. 41st annual meeting of the Chicago Linguistic Society 41, (pp. 251-265). Chicago: CLS.

Kissine, M. (2012). Sentences, utterances, and speech acts. In K. Allan \& K. Jaszczolt (Eds.), Cambridge handbook of pragmatics (pp. 169-190). New York: Cambridge University Press.

Langendoen, T., \& Savin, H. (1971). The projection problem for presuppositions. In C. J. Fillmore \& D. T. Langėndoen (Eds.), Studies in linguistic semantics (pp. 54-60). New York: Irvington. 
Levinson, S. (1983). Pragmatics. Cambridge: Cambridge University Press.

Levinson, S. (2000). Presumptive meanings: The theory of generalized conversational implicature. Cambridge, MA: MIT Press.

Macagno, F. (2012a). Presumptive reasoning in interpretation. Implicatures and conflicts of presumptions. Argumentation, 26(2), 233-265.

Macagno, F. (2012b). Reconstructing and assessing the conditions of meaningfulness. An argumentative approach to presupposition. In H. Ribeiro (Ed.), Inside arguments: Logic and the study of argumentation (pp. 247-268). Newcastle upon Tyne: Cambridge Scholars Publishing.

Macagno, F., \& Walton, D. (2013). Implicatures as forms of argument. In A. Capone, F. Lo Piparo, \& M. Carapezza (Eds.), Perspectives on pragmatics and philosophy (pp. 203-225). Cham: Springer International Publishing.

Macagno, F., \& Walton, D. (2014). Emotive language in argumentation. New York: Cambridge University Press.

Marmor, A. (2008). The pragmatics of legal language. Ratio Juris, 21(4), 423-452.

May, T. (1987). Verbs of result in the complements of raising constructions. Australian Journal of Linguistics, 7, 25-42.

Mel'cuk, I. A. (1997).Vers une linguistique Sens-Texte. Leçon inaugurale, Collège de France, Chaire internationale. http://www.fas.umontreal.ca/LING/olst/FrEng/melcukColldeFr.pdf.

Mey, J. L. (2001). Pragmatics. An introduction. Oxford: Blackwell.

Rescher, N. (2006). Presumption and the practices of tentative cognition. Cambridge: Cambridge University Press.

Rorty, A. O. (1980). Agent regret. In A. Rorty (Ed.), Explaining emotions (pp. 489-506). Berkeley: University of California Press.

Simons, M. (2006). Presupposition without common ground. Unpublished manuscript, Carnegie Mellon University. Available at http://www.hss.cmu.edu/philosophy/simons/ Presupposition\%20without\%20Common\%20Ground.pdf

Simons, M. (2013). On the conversational basis of some presuppositions. In A. Capone, F. Lo Piparo, \& M. Carapezza (Eds.), Perspectives on linguistic pragmatics, perspectives in pragmatics, philosophy \& psychology (2nd ed., pp. 329-348). Cham: Springer.

Sperber, D., \& Wilson, D. (1986). Relevance: Communication and cognition. Oxford: Blackwell.

Sperber, D., \& Wilson, D. (1998). Mood and the analysis of non-declarative sentences. In K. Asa (Ed.), Pragmatics: Critical concepts, vol. II (pp. 262-289). London: Routledge.

Stalnaker, R. (1970). Pragmatics. Synthese, 22(1-2), 272-289.

Stalnaker, R. (1973). Presuppositions. Journal of Philosophical Logic, 2(4), 447-457.

Stalnaker, R. (1974). Pragmatic presuppositions. In M. Munitz \& P. Unger (Eds.), Semantics and philosophy (pp. 197-214). New York: New York University Press.

Stalnaker, R. (2002). Common ground. Linguistics and Philosophy, 25, 701-721.

Walton, D. (1996). Fallacies arising from ambiguity. Dordrecht: Kluwer Academic Publishers.

Walton, D., \& Krabbe, E. (1995). Commitment in dialogue. Albany: State University of New York Press.

Zielinska, D. (2013). The mechanism of the form-content correlation process in the paradigm of socio-natural sciences. In A. Capone, F. Lo Piparo, \& M. Carapezza (Eds.), Perspectives on linguistic pragmatics (pp. 469-522). Cham: Springer. 